\title{
Admission White Blood Cell Count Predicts Short- and Long-Term Mortality in Patients With Acute Aortic Dissection: Data From the MIMIC-III Database
}

\section{Chiyuan Zhang}

Central South University

\section{Zuli Fu}

Central South University

\section{Xuliang Chen}

Central South University

Hui Bai

Central South University

Guoqiang Ling

Central South University

Ruizheng Shi

Central South University

Qian Xu ( $\nabla$ elsiexu403@163.com)

Central South University

\section{Research Article}

Keywords: White blood cell count, Acute aortic dissection, short- and long-term mortality, MIMIC-III databse.

Posted Date: February 22nd, 2021

DOI: https://doi.org/10.21203/rs.3.rs-213794/v1

License: (c) (1) This work is licensed under a Creative Commons Attribution 4.0 International License. Read Full License 


\section{Abstract}

\section{Background}

Inflammation underlies both the pathogenesis and prognosis in patients with acute aortic dissection (AAD). This study aimed to assess the association of ICU admission of white blood cell count (WBCc) with short- and long-term mortality in these patients.

\section{Methods}

Clinical data were extracted from the MIMIC-III V1.4 database. After adjusted to covariables, Cox regression analysis and Kapan-Meier curve were performed to determine the relationship between WBCc on admission and short- and long-term mortality in AAD patients. Subgroup analysis and receiver operating characteristic (ROC) curve analysis were conducted to evaluate the performance of admission WBCc in predicting short- and long-term mortality in patients with AAD.

\section{Results}

A total of 325 eligible patients were divided into 2 groups: normal-WBCc group $(\leq 11 \mathrm{k} / \mathrm{uL})$ and highWBCc group $(>11 \mathrm{~K} / \mathrm{uL})$. In univariate Cox regression analysis, high WBCc was significant risk predictor of 30-days, 90-days, 1-year and 5-years mortality [hazard ratio(HR), 95\%Cl, P. 2.58 1.36-4.91 0.004; 3.16 $1.76-5.700 .000 ; 2.741 .57-4.790 .000 ; 2.101 .23-3.540 .006]$. After adjusting for age and other risks, high WBCc remained a significant predictor of 30-days, 90-days and 1-year mortality in AAD patients (HR, $95 \% \mathrm{Cl}, P .2 .551 .23-5.270 .012 ; 2.881 .44-5.760 .003 ; 2.331 .21-4.470 .011)$. The area under ROC curve of WBCc for predicting 30-days, 90-days, 1-year and 5-year mortality were $0.69,0.70,0.66$ and 0.61, respectively. The results from subgroups analysis showed that there was no interaction in most strata and patients who were younger than 69 years of age or had history of respiratory disease with an elevated WBCc had an excess risk of 30-days mortality (HR, 95\% Cl:, $P: 3.181 .41-7.140 .005 ; 3.841 .05-$ $14.130 .043)$.

\section{Conclusion}

A marked elevated WBCc on admission can predict short- and long-term mortality in patients with AAD.

\section{Background}

Acute aortic dissection (AAD) is a devastating cardiovascular disease with urgent onset, rapid progression, and high mortality[1]. Statistics figures showed that the mortality rate of AAD was an increase of $1-2 \%$ per hour after the onset of symptoms[2], and was ranged from 36 to $72 \%$ in the intensive care unit (ICU) during first 48 hours[3]. Thus, identification of risk factors for prognosis is of great value for risk stratification and management in patients with AAD. 
Inflammation is involved in the occurrence and development of $A A D[4,5]$. In recent years, some inflammatory biomarkers, such as D-dimer[6], C-reactive protein (CRP)[7], platelet count (PLTC)[8] and fibrinogen[9] have been shown to be related with the prognosis of AAD patients, but these results are controversial and need to be further verified in larger population and longer follow-up time. White blood cell count (WBCC) is a commonly used non-specific marker of the acute inflammatory response. It has been regarded as an independent risk factor for detecting vascular inflammation and predicting cardiovascular risk[10]. Recently, elevated WBCc on admission was reported to be associated with increased in-hospital mortality in patents with type $A$ and type $B A A D[11,12]$. However, the data regarding the association of admission WBCc and long-term outcomes were poorly defined in these patients. Therefore, the present study aimed to evaluate and analyze the prognostic of admission WBCc on shortand long-term mortality among ICU patients with AAD.

\section{Methods}

This was a retrospective study based on a publicly available Medical Information Mart for Intensive Care (MIMIC) III database. It is a large, single-center database containing comprehensive medical information for more than 60,000 ICU admissions at Beth Israel Deaconess Medical Center (BIDMC) in Boston, Massachusetts from 2001 to 2012[13]. MIMIC-III data are Health Insurance Portability and Accountability Act of 1996 (HIPAA) compliant, and all investigators with data access (MEG,RG) were approved by PhysioNet. Information available in MIMIC-III includes general information (i.e., demographics, insurance, ethnicity, etc.), treatment process (i.e., charted clinical observations, laboratory tests, physiological scores, medications, surgery, etc.) and survival data.

We included patients with AAD including both Stanford type A and type B based on the International Classification of Diseases 9th Edition(ICD-9) code in MIMIC-III database. Of these patients, we excluded those including: 1 ) patients aged $<18$ years or $>80$ years; 2 ) patients who had a clear etiology, such as Marfan syndrome, iatrogenic $A D$ secondary to cardiac surgery, a history of surgery for $A D$, or chronic $A D$; 3) no WBCc data; 4) missing individual data including demographics,laboratory tests, comorbidities, etc. more than $5 \%$. Enrolled AAD patients were divided into 2 groups according to the admission WBCc>11 $\mathrm{K} / \mathrm{uL}$ and $\leq 11 \mathrm{~K} / \mathrm{uL}$ as a cut-off value for normal. The complete process was shown in Fig. 1.

Data extraction was performed through Structured Query Language (SQL) with PostgreSQL 9.6. Baseline characteristics after ICU admission were collected, including demographics (age, gender, ethnicity, etc.), vital signs, laboratory tests, comorbidities, severity score and other data. Vital signs included systolic blood pressure (SBP), diastolic blood pressure (DBP), and mean blood pressure (MBP). The laboratory parameters including red blood cell (RBC), red cell distribution width (RDW), hemoglobin (HB), hematocrit $(\mathrm{HCT})$, platelet (PLT); activated partial thromboplastin time (APTT), prothrombin tmie (PT), international normalized ratio (INR); blood urea nitrogen (BUN), Creatinine (Cr); glucose; serum potassium, sodium, chlorine, magnesium, and total calcium were measured during the admission. Comorbidities including hypertension; diabetes; hypercholesterolemia (HC); valvular disease; stroke; coronary artery disease (CAD); congestive heart failure (CHF); atrial fibrillation (AF); liver disease; respiratory disease, acute kidney 
injury (AKI) and renal replacement therapy (RRT) were also collected for analysis based on the recorded ICD-9 codes in the MIMIC-III database. Severity score included sequential organ failure assessment (SOFA) score; simplified acute physiology score (SAPS II); oxford acute severity of illness score (OASIS) and systemic inflammatory response syndrome (SIRS) score.

Shapiro-Wilk tests were used to examine whether the continuous variables conform to the normal distribution. Normally distributed continuous variables were presented as the mean \pm SD and nonnormally distributed continuous variables were presented as the median and interquartile range (IQR). Categorical variables were presented by number and percentage. Continuous data were compared using Student $t$ test or Mann-Whitney $\mathrm{U}$ test and categorical data were compared using chi-squared test as appropriate. Survival rates within normal-WBCc and high-WBCc groups were determined using KaplanMeier curve and compared using the log-rank tests. Univariate and multivariate Cox proportional hazards analyses were used to evaluate the predictive effect of WBCc in 30-days, 90-days, 1-year and 5-years mortality with hazard ratios (HRs) and $95 \%$ confidence intervals (Cls). Other variables selected for testing in the multivariate analysis were variables with a $P$ value $<0.05$ in the univariate models. Subgroup analyses were conducted to evaluate the WBCc and 30-days morality in different subgroups, including gender; age; hypertension; diabetes; $\mathrm{HC}$; valvular disease; CHF; AF; liver disease; respiratory disease; AKI and RRT. ROC curve analyses and calculation of AUC were used to examine the performance of WBCc in predicting short- and long-term morality. A $P$ value $<0.05$ was considered statistically significant. All of the statistical analyses were performed by the EmpowerStats ver 2.17.8 (http://www.empowerstats.com/cn/,X\&Y solutions, Inc., Boston, MA) and R software vers 3.42.

The raw data showed in this study are fully available in MIMIC-III database.

\section{Results}

After reviewing the data of 380 AAD patients, a total of 325 eligible patients were enrolled in this study (detailed flow chart of patients' selection shown in Fig. 1). The baseline characteristics of all patients are summarized in Table 1. The mean age of all patients was 68.0 (55.4-77.2) years, and $63.1 \%$ of patients $(205 / 325)$ were male. According to admission WBCc, patients were divided into 2 groups including normal-WBCc group and high-WBCc group ( $\leq 11 \mathrm{~K} / \mathrm{uL} ;>11 \mathrm{~K} / \mathrm{uL}$ ). Patients with an elevated WBCc had higher PLT, HCT, Hb, BUN and Glucose. Additionally, these patients had more CHF and higher SAPS II and SIRS scores (all $P<0.05$ ).

During the 5-years follow-up, 98 patients died. The overall 30-, 90-days and 1-, 5-years mortality rate were $14.8 \%$ (48/325), 18.8\% (61/325), 22.8\% (74/325) and 30.2\% (98/325), respectively. As shown in Fig. 2 (ad), the Kaplan-Meier analysis indicated that the survival rate of high-WBCc group was significantly lower than normal-WBCc group during the 4 periods (log-rank $P$ : $<0.05 ;<0.01 ;<0.01 ;<0.01$ ).

In order to explore the association between admission WBCc and short- and long-term mortality, Cox regression analysis was performed and listed in Table 2. In the univariate Cox regression analysis, compared with the referent group (normal-WBCc: $\leq 11 \mathrm{~K} / \mathrm{uL}$ ), high WBCc was a significant predictor of $30-$ 
days, 90-days, 1-year and 5-years mortality in patients with AAD (HR, 95\%Cl, P. 2.58 1.36-4.91 0.004; $3.161 .76-5.700 .000 ; 2.741 .57-4.790 .000 ; 2.101 .23-3.54$ 0.006). In the multivariate Cox regression analysis, after adjusting to age, hypertension, valvular disease, stroke, CHF, atrial fibrillation, renal disease and BUN, high-WBCc remained a significant predictor of 30-days, 90-days and 1-year mortality in AAD patients(HR, 95\% Cl, P. 2.55 1.23-5.27 0.012; 2.88 1.44-5.76 0.003; 2.33 1.21-4.47 0.011), but not a predictor of 5 -years mortality $(\mathrm{HR}=1.61,95 \% \mathrm{Cl}: 0.88-2.95, P=0.12)$. Moreover, as shown in Table 3 , the AUC of level in predicting 30-days, 90-days, 1-year and 5-year mortality were 0.69, 0.70, 0.66 and 0.61, respectively. Compared with other classic severity scores, WBCc showed a better performance than SIRS score.

For further analysis, patients were divided into different subgroups (gender, age, hypertension, diabetes, $\mathrm{HC}$, valvular disease, $\mathrm{CHF}$, AF, liver disease, respiratory disease, AKI and RRT). As shown in Table 4, the results showed that there was no interaction in most strata $(P$ for interaction $=0.13-1.00)$. Patients who were younger than 69 years of age or had a history of respiratory disease with an elevated WBCc had an excess risk of 30-days mortality (HR, 95\% Cl:, P. 3.18 1.41-7.14 0.005; 3.84 1.05-14.13 0.043).

\section{Discussion}

This observational retrospective study based on a large sample cohort analyzed the association of admission WBCc in AAD patients with short- and long-term clinical outcomes. Our results indicated that a high-WBCc on admission in patients with AAD was associated with poor short- and long-term clinical outcomes. After adjustment using a multivariate Cox analysis, the WBCc is an independent predictor to short-term (30-days and 90-days) and long-term (1-year) mortality. AUC analysis indicated that the WBCC had a better performance than SIRS score in predicting short- and long-term mortality in patients with AAD. Moreover, a subgroup analysis showed that high-WBCc on admission carried an excess risk of 30days mortality in patients who were younger than 69 years of age or had a history of respiratory disease.

$A A D$ is an acutely presenting, serve disease with high mortality [14]. Identification of risk factors for prognosis is of great value for risk stratification in AAD patients, but simple and effective biomarker is still lack. Inflammation is involved in medial degradation of aortic artery, arterial wall remodeling, which contributed to aortic wall weakness and rupture[15, 16]. In recent decades, studies showed that several indicators of the inflammatory reaction including CRP level[17], D-dimer level[18] and PLTc[19] were associated with clinical outcomes in acute aortic syndrome(AAS). The WBCc is a sensitive and nonspecific inflammation biomarker and its elevation also has been observed in AAD patients in previous studies[11, 12, 20, 21]. However, the results of further studies on the association between the WBCc and prognosis of patients with AAD were inconsistent. A French study[20] with a Western cohort showed that there was no association between the admission WBCc and in-hospital mortality in both type A and type B AAD patients $(\mathrm{OR}=2.80,95 \% \mathrm{Cl}$ : 0.80-12.58, $P=0.12)$, but its sample size was relatively $\mathrm{small}(\mathrm{n}=94)$. Recently, two studies from China[11, 12] respectively found that, in patients with type $A$ or $B$ AAD, the admission WBCc could predict in-hospital death, but failed to long-term outcomes. The differences in genetic background, type of AD and sample size may partially explain the inconsistency of results. 
In the present study, approximately a quarter of AAD patients showed an elevated WBCc on admission. These patients had higher PLT, HCT, Hb, BUN and Glucose, and had more CHF, higher SAPS II and SIRS scores. Our results revealed that the WBCc is an independent predictor to short-term (30-days and 90days) mortality, which confirmed previous findings from the two Chinese studies. Moreover, a novel finding is that the admission WBCc but also can predict long-term (1-year) mortality. Although the result of the multivariate Cox analysis of 5-years mortality did not reach statistical significance, since the 5years mortality rate was significantly higher in high-WBCC AAD patients, univariate Cox regression analysis showed that WBCC was associated with 5-years mortality and sample size of high-WBCC patients with AAD was relatively small $(n=80)$, we could not easily conclude that there is no association between 5 -years mortality and admission WBCc. The results from subgroup analysis and AUC analysis also proved an excellent performance of the WBCc in predicting short- and long-term mortality in AAD patients. Compared with other classic severity scores, the WBCc showed a better performance than SIRS score. The White blood cell (WBC) is an inflammatory reactant in the early stage of AAD. It has been proved that it can activate endothelial damage, procoagulant effects and microvascular damage, resulting in release of pro-inflammatory cytokines that contribute to a profound degradation of collagen and the extracellular matrix (ECM) related to smooth muscle cell (SMC) depletion, elastic fiber fragmentation and atherosclerosis underling aortic wall irreversible remodeling and weakness, which promote the progression of AAD[15]. In addition, clinical studies showed that an increased WBCc on admission was related to some serious postoperative complications, such as sepsis, hemorrhage, delirium, stroke and myocardial infarction, and might be one of the reasons for the poor prognosis and death[22-25]. Perhaps, these explain why the high-WBCc are associated with poor clinical short- and long-term outcomes in patients with AAD.

In the subgroup analysis, there was no interaction in most strata, which proved the reliability of the WBCc on admission predicting short- and long-term mortality in patients with AAD. We also found that AAD patients who were younger than 69 years of age or had a history of respiratory disease with an elevated WBCc had an excess risk of 30-days mortality. Firstly, increasing age as an independent risk factor in 30days mortality in AAD patients was showed in several research $[12,26]$. They explained that the great number of pre-existing comorbidities in the elderly patients increased the mortality rate. In our study, younger patients with an increased WBCc had an excess risk of 30-days mortality and it may be because younger patients have fewer underlying diseases than the older, so that the impact of increased WBCc is magnified in this population. Secondly, respiratory disease can aggravate hypoxia and promote acidosis in patients with $A A D$, and these changes further decrease the patients' cardiac contractility and vascular resistance, ultimately leading to circulatory shock and end-organ failure. Thus, it could be the main reason for higher risk of 30-days mortality in AAD patients who had a history of respiratory disease with an elevated WBCc. Our results indicated that more severe measures need to be taken in both of the above situations.

It is first time to reveal the potential value of the WBCc as a prognostic biomarker of both in short- and long-term mortality in AAD patients. Combined with previous studies, our results provide further evidence of the utility of this stable and convenient indicator predicting prognosis in AAD patients. In the future, 
additional researches are needed to further understand the role of different types of WBC or some of their components in the prognosis of AAD patients, which provide the possibility for the application of targeted intervention in the treatment of AAD.

There are several limitations need to be mentioned in the study. Firstly, this study is a single-center observation study, which may not be universally representative. However, the reliability of our results was strongly enhanced by large sample size from MIMIC-III database and most subgroups analysis having no interaction. Secondly, our study only analyzed the WBCc on admission. Observation of changes of the WBCc in different time periods may provide more valuable information for evaluating its prognostic value in AAD patients. Thirdly, more in-depth mechanism exploration should be conducted in the future.

\section{Conclusions}

In summary, the present study indicated that high-WBCc on admission is an independent predictor for the short- and long-term mortality in patients with AAD.

\section{Abbreviations}

AAD: acute aortic dissection; WBCc: white blood cell count; ROC: receiver operating characteristic; ICU: intensive care unit; CRP: C-reactive protein; PLTC: platelet count; MIMIC: Medical Information Mart for Intensive Care; BIDMC: Beth Israel Deaconess Medical Center; HIPAA: Health Insurance Portability and Accountability Act of 1996; ICD-9: International Classification of Diseases 9th Edition; SQL: Structured Query Language; SBP: systolic blood pressure; DBP: diastolic blood pressure; MBP: mean blood pressure; RBC: red blood cell; RDW: red cell distribution width; HB: hemoglobin; HCT: hematocrit; PLT: platelet; APTT: activated partial thromboplastin time; PT: prothrombin time; INR: international normalized ratio; BUN: blood urea nitrogen; Cr: Creatinine; HC: hypercholesterolemia; CAD: coronary artery disease; CHF: congestive heart failure; AF: atrial fibrillation; AKI: acute kidney injury; RRT: renal replacement therapy; SOFA: sequential organ failure assessment; SAPS II: simplified acute physiology score; OASIS: oxford acute severity of illness score; SIRS: systemic inflammatory response syndrome; IQR: interquartile range; HRs: hazard ratios; Cls: confidence intervals; AAS: acute aortic syndrome; WBC: White blood cell; ECM: extracellular matrix; SMC: smooth muscle cell.

\section{Declarations}

\section{Acknowledgments}

We would like to thank Prof. Liao Tan for statistical assistance.

\section{Author' contributions}

Chiyuan Zhang and Zuli Fu contributed equally to this work. Qian Xu conceptualized this research aim, planned the analyses and guided the literature review. Hui Bai and Xuliang Chen extracted the data from 
the MIMIC-III database. Chiyuan Zhang and Zuli Fu participated in processing and analyzing the data. Chiyuan Zhang wrote the first draft of the paper. Guoqiang Ling and Ruizheng Shi revised and commented on the draft and overall responsibility. All authors read and approved the final manuscript.

\section{Funding}

Not applicable

\section{Availability of data and materials}

The datasets generated and/or analysed during the current study are available in the Physionet repository, https ://physionet.org/physiobank/database/mimic 3cdb.

\section{Ethics approval and consent to participate}

The establishment of this database was approved by the Massachusetts Institute of Technology (Cambridge, MA) and Beth Israel Deaconess Medical Center (Boston, MA), and consent was obtained for the original data collection. Therefore, the ethical approval statement and the need for informed consent were waived for this manuscript.

\section{Consent to publish}

Not applicable

\section{Competing interests}

The authors declare that they have no competing interests.

\section{References}

1. Nienaber CA, Clough RE. Management of acute aortic dissection. Lancet (London, England). 2015;385(9970):800-11.

2. Nienaber CA, Eagle KA. Aortic dissection: new frontiers in diagnosis and management: Part I: from etiology to diagnostic strategies. Circulation. 2003;108(5):628-35.

3. Evangelista A, Isselbacher EM, Bossone E, Gleason TG, Eusanio MD, Sechtem U, et al. Insights From the International Registry of Acute Aortic Dissection: A 20-Year Experience of Collaborative Clinical Research. Circulation. 2018;137(17):1846-60.

4. Nienaber CA, Clough RE, Sakalihasan N, Suzuki T, Gibbs R, Mussa F, et al. Aortic dissection. Nature reviews Disease primers. 2016;2:16053.

5. Liu Z, Luo H, Zhang L, Huang Y, Liu B, Ma K, et al. Hyperhomocysteinemia exaggerates adventitial inflammation and angiotensin II-induced abdominal aortic aneurysm in mice. Circulation research. 2012;111(10):1261-73. 
6. Mori K, Tamune H, Tanaka H, Nakamura M. Admission Values of D-dimer and C-reactive Protein (CRP) Predict the Long-term Outcomes in Acute Aortic Dissection. Internal medicine (Tokyo, Japan). 2016;55(14):1837-43.

7. Wen D, Du X, Dong JZ, Zhou XL, Ma CS. Value of D-dimer and C reactive protein in predicting inhospital death in acute aortic dissection. Heart (British Cardiac Society). 2013;99(16):1192-7.

8. Li DZ, Chen QJ, Sun HP, Zeng R, Zeng Z, Gao XM, et al. Mean platelet volume to platelet count ratio predicts in-hospital complications and long-term mortality in type A acute aortic dissection. Blood coagulation \& fibrinolysis: an international journal in haemostasis and thrombosis. 2016;27(6):6539.

9. Guan X, Gong M, Wang X, Zhu J, Liu Y, Sun L, et al. Low preoperative fibrinogen level is risk factor for neurological complications in acute aortic dissection. Medicine. 2018;97(21):e10830.

10. Shah B, Baber U, Pocock SJ, Krucoff MW, Ariti C, Gibson CM, et al. White Blood Cell Count and Major Adverse Cardiovascular Events After Percutaneous Coronary Intervention in the Contemporary Era: Insights From the PARIS Study (Patterns of Non-Adherence to Anti-Platelet Regimens in Stented Patients Registry). Circulation Cardiovascular interventions. 2017;10(9).

11. Fan X, Huang B, Lu H, Zhao Z, Lu Z, Yang Y, et al. Impact of Admission White Blood Cell Count on Short- and Long-term Mortality in Patients With Type A Acute Aortic Dissection: An Observational Study. Medicine. 2015;94(42):e1761.

12. Chen ZR, Huang B, Lu HS, Zhao ZH, Hui RT, Yang YM, et al. Admission white blood cell count predicts short-term clinical outcomes in patients with uncomplicated Stanford type B acute aortic dissection. Journal of geriatric cardiology: JGC. 2017;14(1):49-56.

13. Johnson AE, Pollard TJ, Shen L, Lehman LW, Feng M, Ghassemi M, et al. MIMIC-III, a freely accessible critical care database. Scientific data. 2016;3:160035.

14. Mussa FF, Horton JD, Moridzadeh R, Nicholson J, Trimarchi S, Eagle KA. Acute Aortic Dissection and Intramural Hematoma: A Systematic Review. Jama. 2016;316(7):754-63.

15. Cifani N, Proietta M, Tritapepe L, Di Gioia C, Ferri L, Taurino M, et al. Stanford-A acute aortic dissection, inflammation, and metalloproteinases: a review. Annals of medicine. 2015;47(6):441-6.

16. Xu H, Du S, Fang B, Li C, Jia X, Zheng S, et al. VSMC-specific EP4 deletion exacerbates angiotensin IIinduced aortic dissection by increasing vascular inflammation and blood pressure. Proceedings of the National Academy of Sciences of the United States of America. 2019;116(17):8457-62.

17. Vrsalović M, Vrsalović Presečki A. Admission C-reactive protein and outcomes in acute aortic dissection: a systematic review. Croatian medical journal. 2019;60(4):309-15.

18. Gorla R, Erbel R, Kahlert P, Tsagakis K, Jakob H, Mahabadi AA, et al. Diagnostic role and prognostic implications of D-dimer in different classes of acute aortic syndromes. European heart journal Acute cardiovascular care. 2017;6(5):379-88.

19. Huang B, Tian L, Fan X, Zhu J, Liang Y, Yang Y. Low admission platelet counts predicts increased risk of in-hospital mortality in patients with type $A$ acute aortic dissection. International journal of cardiology. 2014;172(3):e484-6. 
20. Shimada S, Nakamura H, Kurooka A, Nishioka N, Sugimura K, Ino H, et al. Fever associated with acute aortic dissection. Circulation journal: official journal of the Japanese Circulation Society. 2007;71(5):766-71.

21. Wen $D$, Wu HY, Jiang XJ, Zhang HM, Zhou XL, Li JJ, et al. Role of plasma C-reactive protein and white blood cell count in predicting in-hospital clinical events of acute type A aortic dissection. Chinese medical journal. 2011;124(17):2678-82.

22. Arnaoutoglou E, Kouvelos G, Tzimas P, Laou E, Bouris V, Papadopoulos G, et al. Relationship between normal preoperative white blood cell count and major adverse events after endovascular repair for abdominal aortic aneurysm: results of a pilot study. Journal of clinical anesthesia. 2017;36:201-5.

23. Garbens A, Wallis CJD, Bjarnason G, Kulkarni GS, Nathens AB, Nam RK, et al. Platelet to white blood cell ratio predicts 30-day postoperative infectious complications in patients undergoing radical nephrectomy for renal malignancy. Canadian Urological Association journal = Journal de I'Association des urologues du Canada. 2017;11(11):E414-e20.

24. Heredia-Rodríguez M, Bustamante-Munguira J, Lorenzo M, Gómez-Sánchez E, Álvarez FJ, Fierro I, et al. Procalcitonin and white blood cells, combined predictors of infection in cardiac surgery patients. The Journal of surgical research. 2017;212:187-94.

25. Kotfis K, Ślozowska J, Safranow K, Szylińska A, Listewnik M. The Practical Use of White Cell Inflammatory Biomarkers in Prediction of Postoperative Delirium after Cardiac Surgery. Brain sciences. 2019;9(11).

26. Jonker FH, Trimarchi S, Muhs BE, Rampoldi V, Montgomery DG, Froehlich JB, et al. The role of age in complicated acute type B aortic dissection. The Annals of thoracic surgery. 2013;96(6):2129-34.

\section{Tables}


Table 1

Baseline characteristics of patients according to admission WBCc.

\begin{tabular}{|c|c|c|c|c|}
\hline Characteristics & Total $(n=325)$ & White blo & $(\mathrm{K} / \mathrm{uL})$ & $p$ Value \\
\hline & & $\leq 11$ & $>11$ & \\
\hline & & $(n=245)$ & $(n=80)$ & \\
\hline
\end{tabular}

Demographics

Gender

0.145

Male

$205(63.1 \%)$

$160(65.3 \%)$

$45(56.3 \%)$

Female

$120(36.9 \%)$

$85(34.7 \%)$

$35(43.8 \%)$

Age, years

$67.98(55.40-77.21)$

$69.0(55.0-77.0)$

$64.5(55.0-77.0)$

0.378

Insurance

0.786

Government

20 (6.2\%)

16 (6.5\%)

$4(5.0 \%)$

Medicaid

15 (4.6\%)

11 (4.5\%)

4 (5.0\%)

Medicare

171 (52.6\%)

130 (53.1\%)

41 (51.3\%)

Private

114 (35.1\%)

83 (33.9\%)

31 (38.8\%)

Selfpay

$5(1.5 \%)$

$5(2.0 \%)$

$0(0.0 \%)$

Ethnicity

0.846

White

222 (68.3\%)

166 (67.8\%)

$56(70.0 \%)$

Black

44 (13.5\%)

32 (13.1\%)

$12(15.0 \%)$

Hispanic

$13(4.0 \%)$

11 (4.5\%)

2 (2.5\%)

Others

$46(14.2 \%)$

$36(14.7 \%)$

$10(12.5 \%)$

Dissection site

0.152

Thoracic

181 (55.7\%)

143 (58.4\%)

38 (47.5\%)

Abdominal

57 (17.5\%)

38 (15.5\%)

$19(23.8 \%)$

Thoracoabdominal

$87(26.8 \%)$

$64(26.1 \%)$

$23(28.8 \%)$

Sanford Type

0.058

HC: hypercholesterolemia; CAD: coronary artery disease; CHF: congestive heart failure; AKI: acute kidney injury; RRT: renal replacement therapy; RBC: red blood cell; PLT: platelet; RDW: red cell distribution width; $\mathrm{Hb}$ : hemoglobin; HCT: hematocrit; BUN: blood urea nitrogen; APTT: activated partial thromboplastin time; PT: prothrombin time; INR: international normalized ratio; Total Ca: total calcium; SBP: systolic blood pressure; DBP: diastolic blood pressure; MBP: mean blood pressure; SAPS II: simplified acute physiology score; OASIS: oxford acute severity of illness score; SOFA: sequential organ failure assessment; SIRS: systemic inflammatory response syndrome. 


\begin{tabular}{|c|c|c|c|c|}
\hline \multirow[t]{3}{*}{ Characteristics } & \multirow[t]{3}{*}{ Total $(n=325)$} & \multicolumn{2}{|c|}{ White blood cell count ( $\mathrm{K} / \mathrm{uL}$ ) } & \multirow[t]{3}{*}{ p Value } \\
\hline & & $\leq 11$ & $>11$ & \\
\hline & & $(n=245)$ & $(n=80)$ & \\
\hline A & 219 (67.4\%) & 172 (70.2\%) & $47(58.7 \%)$ & \\
\hline B & $106(32.6 \%)$ & $73(29.8 \%)$ & $33(41.3 \%)$ & \\
\hline \multicolumn{5}{|l|}{ Comorbidities } \\
\hline Hypertension & $192(59.1 \%)$ & $142(58.0 \%)$ & $50(62.5 \%)$ & 0.473 \\
\hline Diabetes & $27(8.3 \%)$ & $19(7.8 \%)$ & $8(10.0 \%)$ & 0.528 \\
\hline $\mathrm{HC}$ & $50(15.4 \%)$ & $38(15.5 \%)$ & $12(15.0 \%)$ & 0.913 \\
\hline Valvular disease & $33(10.2 \%)$ & $22(9.0 \%)$ & $11(13.8 \%)$ & 0.220 \\
\hline Stroke & $25(7.7 \%)$ & $18(7.3 \%)$ & $7(8.8 \%)$ & 0.683 \\
\hline CAD & $58(17.8 \%)$ & $44(18.0 \%)$ & $14(17.5 \%)$ & 0.926 \\
\hline CHF & $29(8.9 \%)$ & $11(4.5 \%)$ & $18(22.5 \%)$ & 0.000 \\
\hline Atrial fibrillation & $56(17.2 \%)$ & $42(17.1 \%)$ & $14(17.5 \%)$ & 0.941 \\
\hline Renal disease & $45(13.8 \%)$ & $30(12.2 \%)$ & $15(18.8 \%)$ & 0.144 \\
\hline Liver disease & $10(3.1 \%)$ & $9(3.7 \%)$ & $1(1.3 \%)$ & 0.461 \\
\hline $\begin{array}{l}\text { Respiratory } \\
\text { disease }\end{array}$ & $63(19.4 \%)$ & $49(20.0 \%)$ & $14(17.5 \%)$ & 0.623 \\
\hline AKI & $133(40.9 \%)$ & $96(39.2 \%)$ & $37(46.3 \%)$ & 0.264 \\
\hline RRT & $29(8.9 \%)$ & $20(8.2 \%)$ & $9(11.3 \%)$ & 0.400 \\
\hline \multicolumn{5}{|l|}{ Laboratory test } \\
\hline RBC, K/uL & 3.7 (3.3 4.2) & $3.7 \pm 0.6$ & $3.8 \pm 0.9$ & 0.234 \\
\hline PLT, K/uL & $164.0(119.0 \sim 227.0)$ & $\begin{array}{l}154.0(116.0- \\
220.0)\end{array}$ & $180.5(136.5-265.5)$ & 0.021 \\
\hline RDW, \% & $14.4(13.6 \sim 15.3)$ & $14.4(13.6 \sim 15.4)$ & $14.6(13.7 \sim 15.3)$ & 0.449 \\
\hline
\end{tabular}

$\mathrm{HC}$ : hypercholesterolemia; CAD: coronary artery disease; CHF: congestive heart failure; AKI: acute kidney injury; RRT: renal replacement therapy; RBC: red blood cell; PLT: platelet; RDW: red cell distribution width; Hb: hemoglobin; HCT: hematocrit; BUN: blood urea nitrogen; APTT: activated partial thromboplastin time; PT: prothrombin time; INR: international normalized ratio; Total Ca: total calcium; SBP: systolic blood pressure; DBP: diastolic blood pressure; MBP: mean blood pressure; SAPS II: simplified acute physiology score; OASIS: oxford acute severity of illness score; SOFA: sequential organ failure assessment; SIRS: systemic inflammatory response syndrome. 


\begin{tabular}{|c|c|c|c|c|}
\hline \multirow[t]{3}{*}{ Characteristics } & \multirow[t]{3}{*}{ Total $(n=325)$} & \multicolumn{2}{|c|}{ White blood cell count ( $\mathrm{K} / \mathrm{uL}$ ) } & \multirow[t]{3}{*}{ p Value } \\
\hline & & $\leq 11$ & $>11$ & \\
\hline & & $(n=245)$ & $(n=80)$ & \\
\hline HCT, \% & $28.8(23.0-33.8)$ & $28.0(22.0-33.0)$ & $30.4 \pm 6.9$ & 0.006 \\
\hline $\mathrm{Hb}, \mathrm{g} / \mathrm{dL}$ & $9.7(7.8 \sim 11.5)$ & $9.6(7.6-11.5)$ & $10.3 \pm 2.4$ & 0.029 \\
\hline BUN, mg/dL & $16.0(12.0 \sim 22.0)$ & $15.0(12.0 \sim 20.0)$ & $20.0(15.0 \sim 26.5)$ & 0.000 \\
\hline Creatinine, mg/dL & $1.1(0.8 \sim 1.6)$ & $1.0(1.0-2.0)$ & $1.0(1.0-2.0)$ & 0.064 \\
\hline Chloride, $\mathrm{mmol} / \mathrm{L}$ & $\begin{array}{l}102.0(100.0 \sim \\
105.0)\end{array}$ & $\begin{array}{l}102.0(100.0- \\
105.0)\end{array}$ & $102.4 \pm 4.2$ & 0.899 \\
\hline Glucose, mg/dL & 102.0 (89.0 119.) & $100.0(88.0-116.0)$ & $110.5(91.0-126.0)$ & 0.013 \\
\hline APTT, s & $28.2(25.2 \sim 32.7)$ & $28.4(25.4 \sim 32.7)$ & $27.7(24.4-33.0)$ & 0.571 \\
\hline INR & $1.2(1.1 \sim 1.3)$ & $1.0(1.0-1.0)$ & $1.0(1.0-1.0)$ & 0.148 \\
\hline PT, s & $13.4(12.5 \sim 14.4)$ & $13.4(12.6-14.4)$ & $13.4(12.4 \sim 14.8)$ & 0.769 \\
\hline Sodium, $\mathrm{mmol} / \mathrm{L}$ & $137.0(134.0-139.0)$ & $\begin{array}{l}136.0(134.0- \\
139.0)\end{array}$ & $136.6 \pm 3.3$ & 0.246 \\
\hline Potassium,mmol/L & $3.6(3.3 \sim 3.9)$ & $3.6(3.3-3.9)$ & $3.7 \pm 0.6$ & 0.187 \\
\hline Total Ca2, mg/dL & $8.5(8.1 \sim 9.0)$ & $9.0(8.0-9.0)$ & $8.5(8.0-9.0)$ & 0.618 \\
\hline $\begin{array}{l}\text { Magnesium, } \\
\mathrm{mg} / \mathrm{dL}\end{array}$ & $2.0(1.9 \sim 2.3)$ & $2.0(1.9-2.3)$ & $2.0(1.9 \sim 2.3)$ & 0.633 \\
\hline SBP, $\mathrm{mmHg}$ & $\begin{array}{l}151.0(136.0 \sim \\
164.0)\end{array}$ & $\begin{array}{l}151.0(136.0- \\
164.0)\end{array}$ & $149.5(134.5-164.5)$ & 0.859 \\
\hline $\mathrm{DBP}, \mathrm{mmHg}$ & $81.0(72.0 \sim 91.0)$ & $80.0(72.0-89.0)$ & $82.0(71.0-93.0)$ & 0.504 \\
\hline MAP, mmHg & $102.0(93.0 \sim 112.0)$ & $102.0(93.0-111.0)$ & $103.0(92.5 \sim 114.0)$ & 0.590 \\
\hline \multicolumn{5}{|l|}{ Severity score } \\
\hline SAPSII & $35.0(27.0 \sim 43.0)$ & $34.0(27.0-41.0)$ & $40.5 \pm 14.3$ & 0.003 \\
\hline OASIS & $32.0(27.0 \sim 39.0)$ & $32.0(27.0-37.0)$ & $34.0(26.0-41.5)$ & 0.173 \\
\hline SOFA & $4.0(2.0 \sim 6.0)$ & $4.0(2.0-6.0)$ & $4.0(2.0 \sim 7.0)$ & 0.624 \\
\hline
\end{tabular}

$\mathrm{HC}$ : hypercholesterolemia; CAD: coronary artery disease; CHF: congestive heart failure; AKI: acute kidney injury; RRT: renal replacement therapy; RBC: red blood cell; PLT: platelet; RDW: red cell distribution width; Hb: hemoglobin; HCT: hematocrit; BUN: blood urea nitrogen; APTT: activated partial thromboplastin time; PT: prothrombin time; INR: international normalized ratio; Total Ca: total calcium; SBP: systolic blood pressure; DBP: diastolic blood pressure; MBP: mean blood pressure; SAPS II: simplified acute physiology score; OASIS: oxford acute severity of illness score; SOFA: sequential organ failure assessment; SIRS: systemic inflammatory response syndrome. 


\begin{tabular}{|c|c|c|c|c|}
\hline \multirow[t]{3}{*}{ Characteristics } & \multirow[t]{3}{*}{ Total $(n=325)$} & \multicolumn{2}{|c|}{ White blood cell count ( $\mathrm{K} / \mathrm{uL}$ ) } & \multirow[t]{3}{*}{ p Value } \\
\hline & & $\leq 11$ & $>11$ & \\
\hline & & $(n=245)$ & $(n=80)$ & \\
\hline SIRS & $3.0(2.0 \sim 3.0)$ & $2.0(2.0-3.0)$ & $3.0(3.0 \sim 4.0)$ & 0.000 \\
\hline \multicolumn{5}{|c|}{$\begin{array}{l}\text { HC: hypercholesterolemia; CAD: coronary artery disease; CHF: congestive heart failure; AKI: acute } \\
\text { kidney injury; RRT: renal replacement therapy; RBC: red blood cell; PLT: platelet; RDW: red cell } \\
\text { distribution width; Hb: hemoglobin; HCT: hematocrit; BUN: blood urea nitrogen; APTT: activated partial } \\
\text { thromboplastin time; PT: prothrombin time; INR: international normalized ratio; Total Ca: total } \\
\text { calcium; SBP: systolic blood pressure; DBP: diastolic blood pressure; MBP: mean blood pressure; } \\
\text { SAPS II: simplified acute physiology Score; OASIS: oxford acute severity of illness score; SOFA: } \\
\text { sequential organ failure assessment; SIRS: systemic inflammatory response syndrome. }\end{array}$} \\
\hline
\end{tabular}


Table 2

Hazard Ratio (HR) $(95 \%$ Cls) for mortality across groups of admission WBCc.

\begin{tabular}{|c|c|c|c|c|}
\hline \multirow[t]{2}{*}{ WBCc } & \multicolumn{2}{|l|}{ Non-adjusted } & \multicolumn{2}{|l|}{ Model 1} \\
\hline & HR (95\%Cls) & p Value & HR (95\%Cls) & p Value \\
\hline \multicolumn{5}{|c|}{ 30-days mortality } \\
\hline \multicolumn{5}{|c|}{ WBCc, K/uL } \\
\hline$\leq 11 \mathrm{~K} / \mathrm{uL}$ & 1.0 (ref) & / & 1.0 (ref) & / \\
\hline$>11 \mathrm{~K} / \mathrm{uL}$ & $2.583(1.361-4.905)$ & 0.004 & $2.547(1.231-5.268)$ & 0.012 \\
\hline \multicolumn{5}{|c|}{ 90-days mortality } \\
\hline \multicolumn{5}{|c|}{ WBCc, K/uL } \\
\hline$\leq 11 \mathrm{~K} / \mathrm{uL}$ & 1.0 (ref) & / & 1.0 (ref) & / \\
\hline$>11 \mathrm{~K} / \mathrm{uL}$ & $3.161(1.756-5.693)$ & 0.000 & $2.882(1.444-5.755)$ & 0.003 \\
\hline \multicolumn{5}{|c|}{ 1-year mortality WBCc, K/uL } \\
\hline$\leq 11 \mathrm{~K} / \mathrm{uL}$ & 1.0 (ref) & / & 1.0 (ref) & / \\
\hline$>11 \mathrm{~K} / \mathrm{uL}$ & $2.741(1.569-4.789)$ & 0.000 & $2.326(1.211-4.470)$ & 0.011 \\
\hline \multicolumn{5}{|c|}{ 5-years mortality WBCc, K/uL } \\
\hline$\leq 11 \mathrm{~K} / \mathrm{uL}$ & 1.0 (ref) & / & 1.0 (ref) & / \\
\hline$>11 \mathrm{~K} / \mathrm{uL}$ & $2.090(1.234-3.541)$ & 0.006 & $1.613(0.882-2.951)$ & 0.121 \\
\hline \multicolumn{5}{|c|}{ Non-adjusted model adjusted to: none; } \\
\hline \multicolumn{5}{|c|}{$\begin{array}{l}\text { Adjusted model } 1 \text { adjusted to: age, hypertension, valvular disease, stroke, CHF, atrial fibrillation, renal } \\
\text { disease and BUN. }\end{array}$} \\
\hline \multicolumn{5}{|c|}{$\begin{array}{l}\text { HR: Hazard Ratio; WBCc: White blood cell count; CHF: congestive heart failure; BUN: blood urea } \\
\text { nitrogen. }\end{array}$} \\
\hline
\end{tabular}

Due to technical limitations, table 3 is only available as a download in the Supplemental Files section. 
Table 4

Subgroup analysis of the association with admission WBCc and 30-days mortality.
Number WBCc
$p$ for
Of
interaction
patients $\leq 11 \mathrm{~K} / \mathrm{uL} \quad \mathrm{p}$ Value $>11 \mathrm{~K} / \mathrm{uL}$

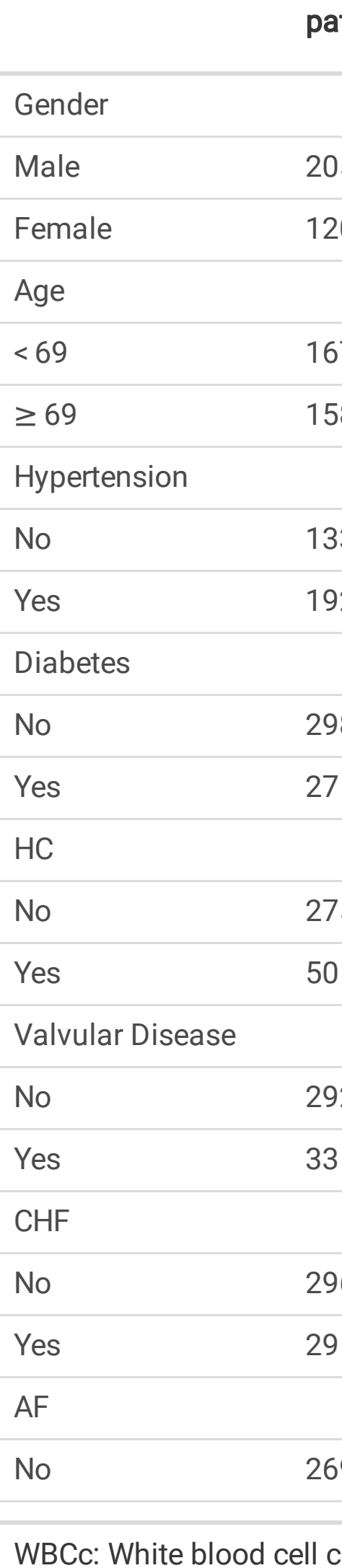

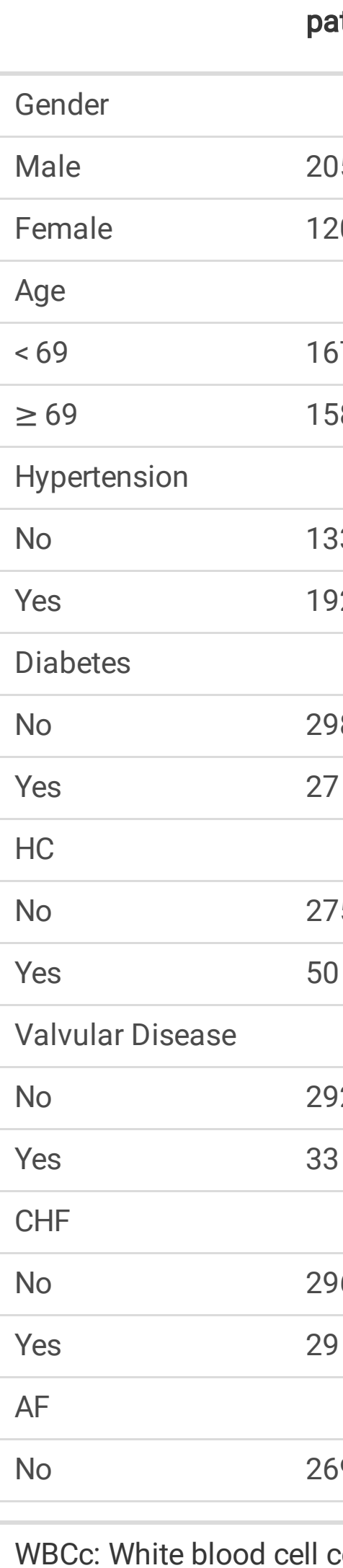

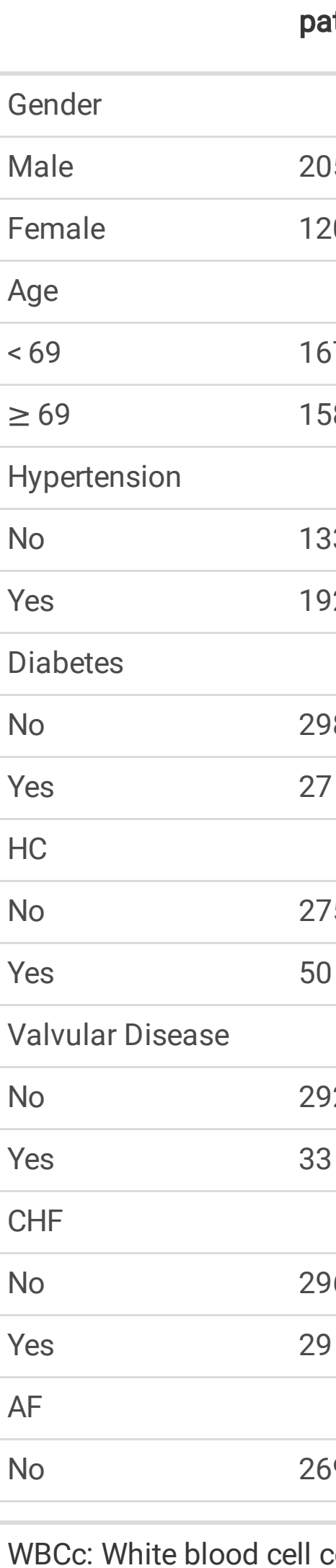

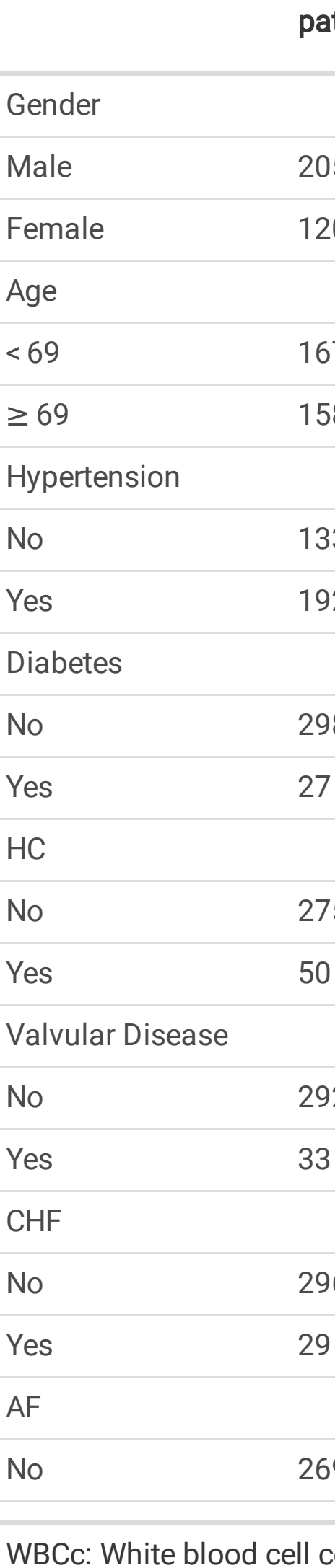

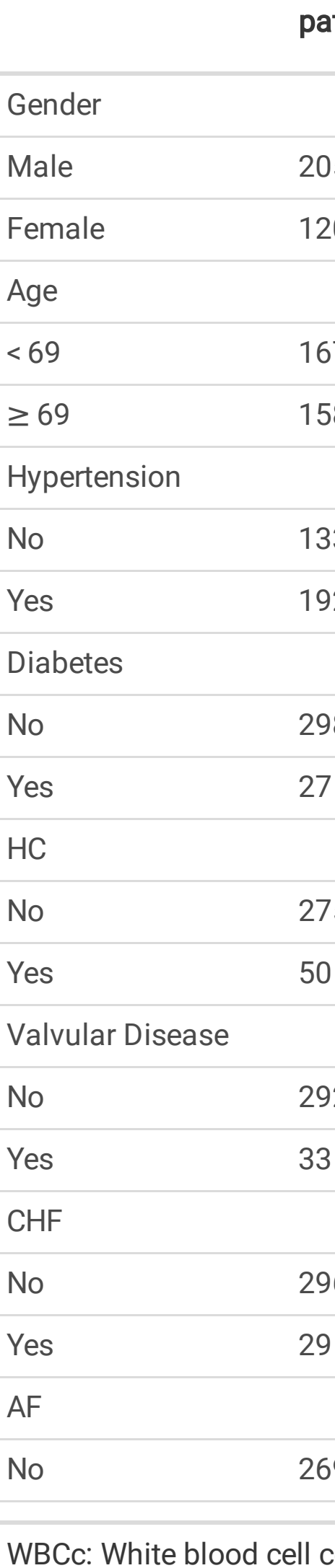

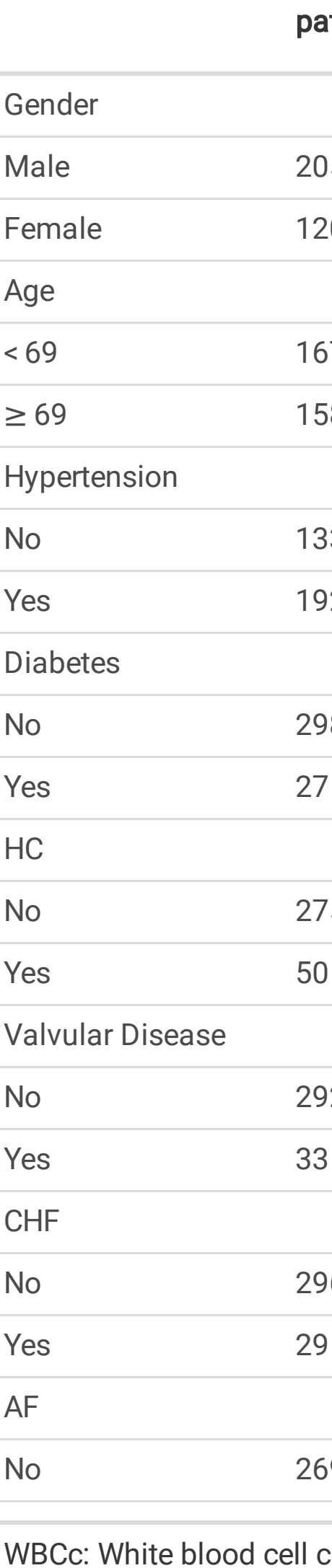

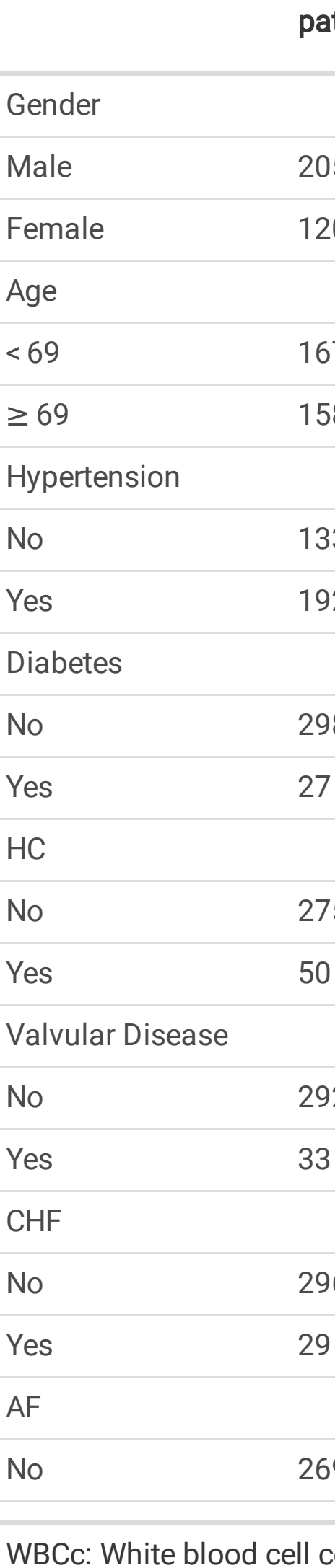

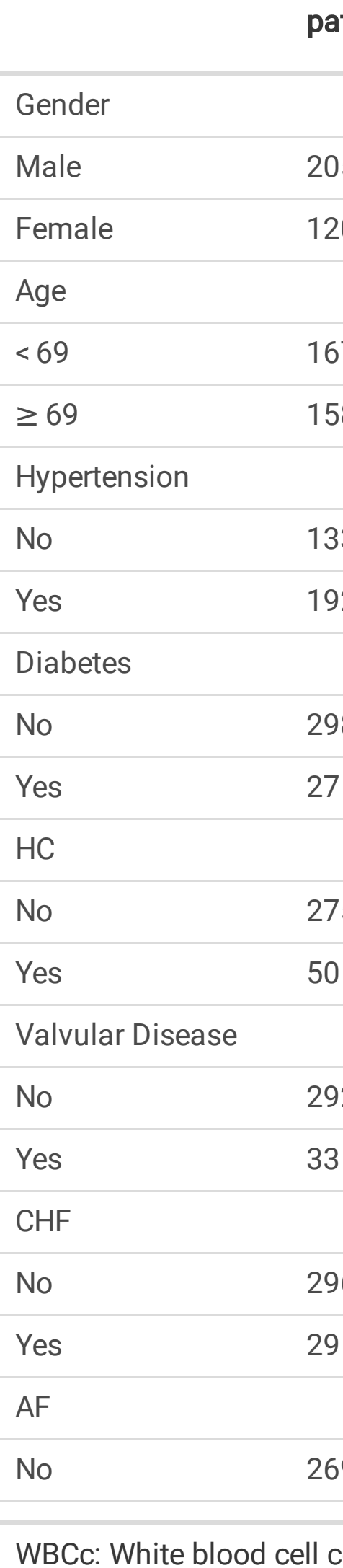

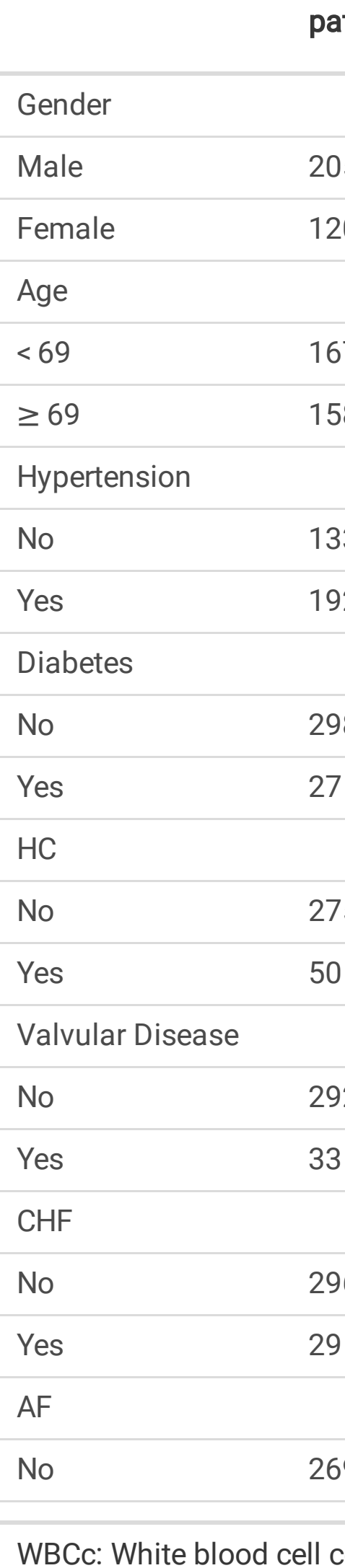

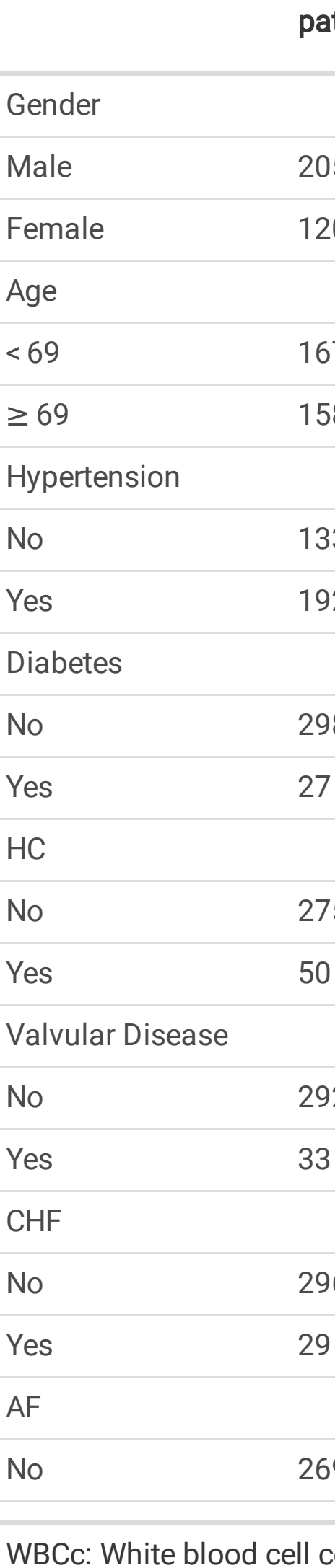

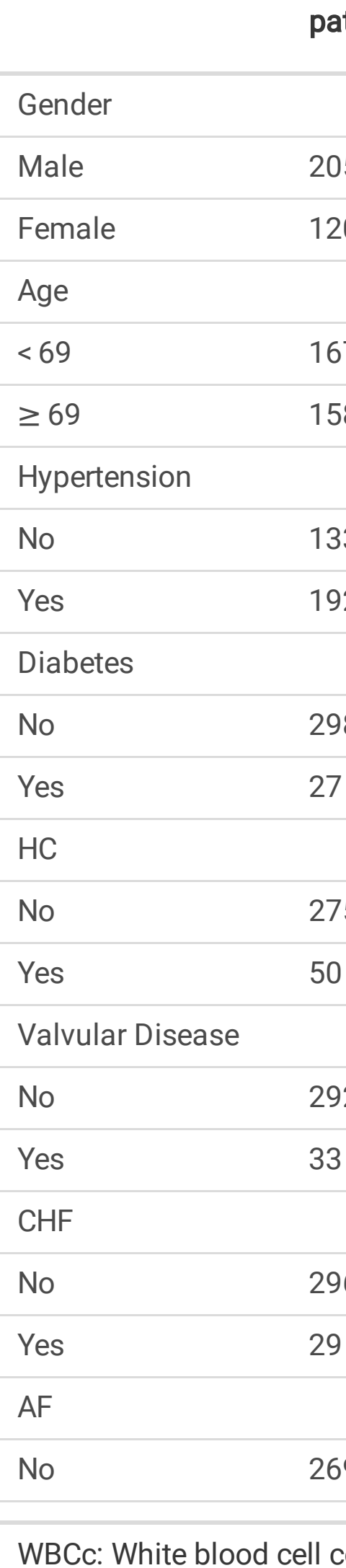

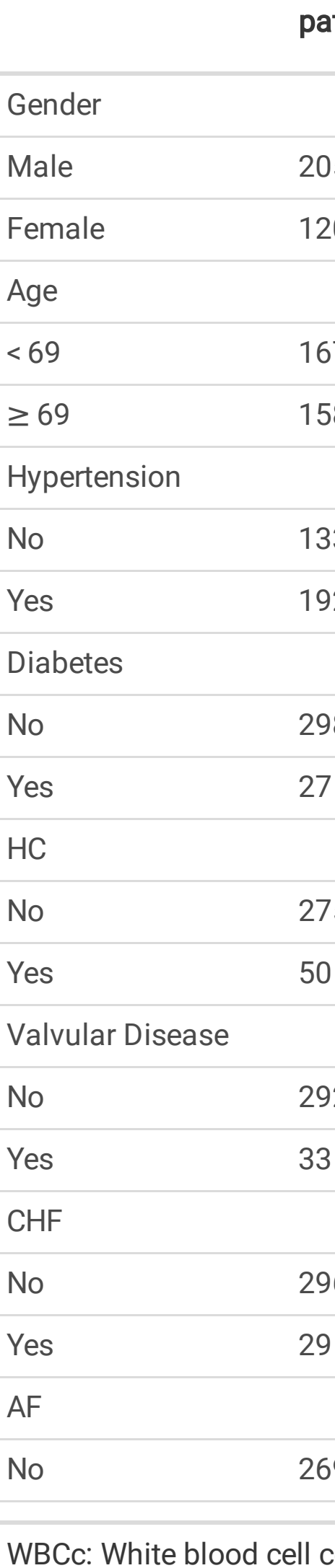

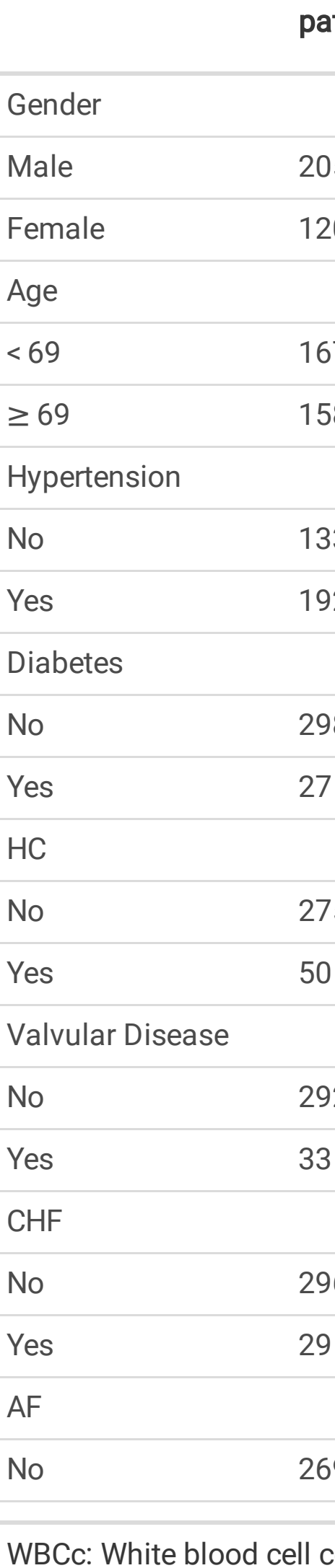

No

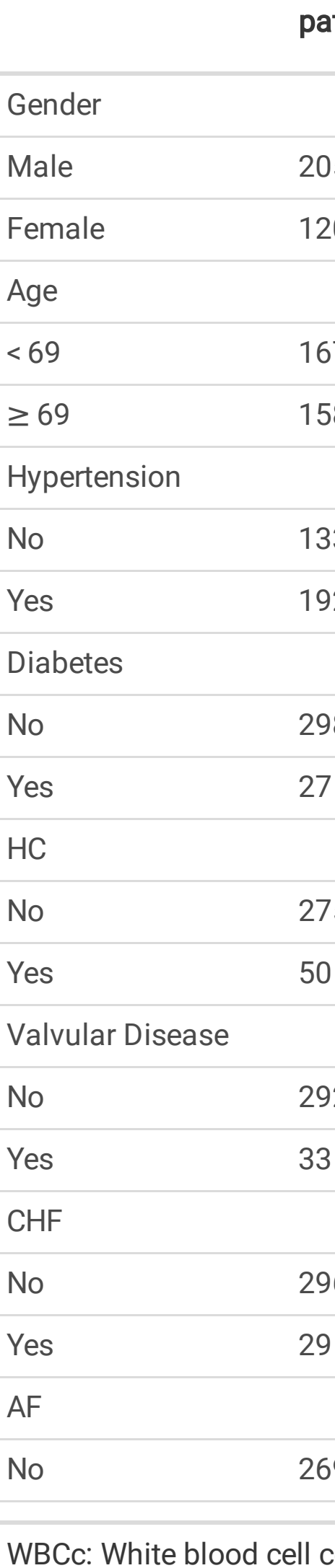

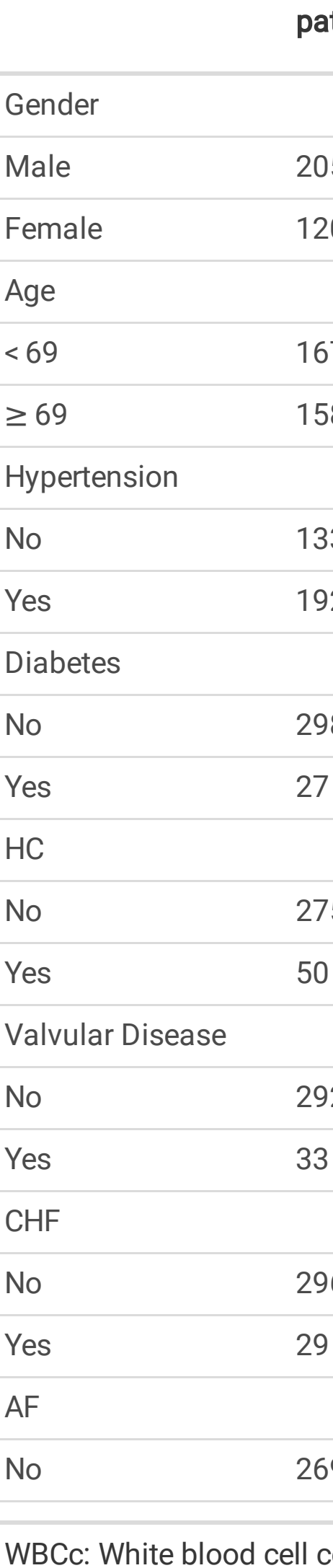

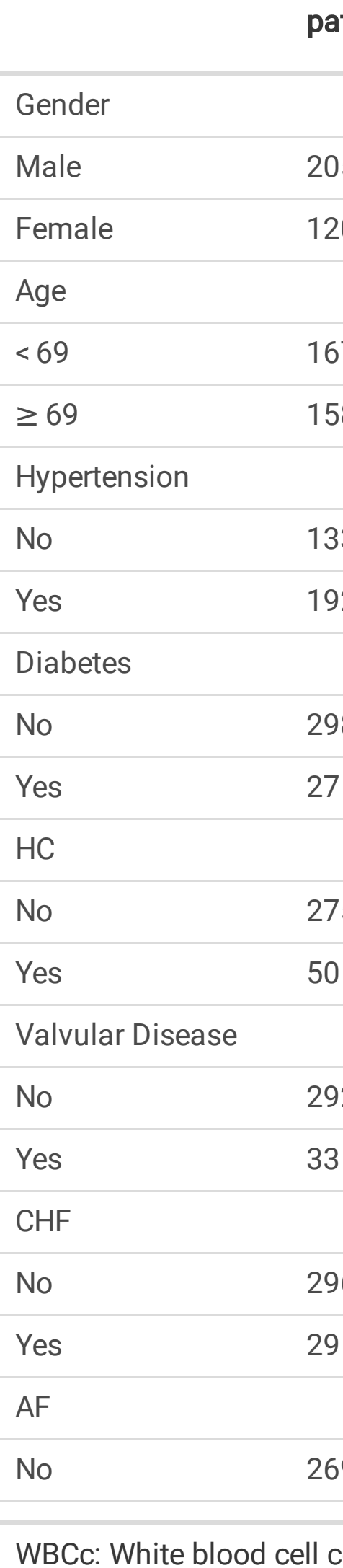

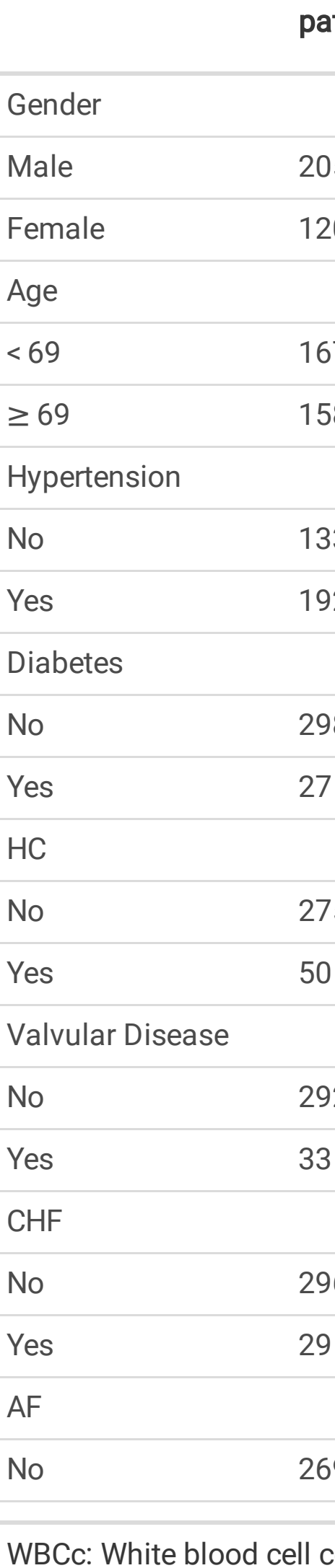

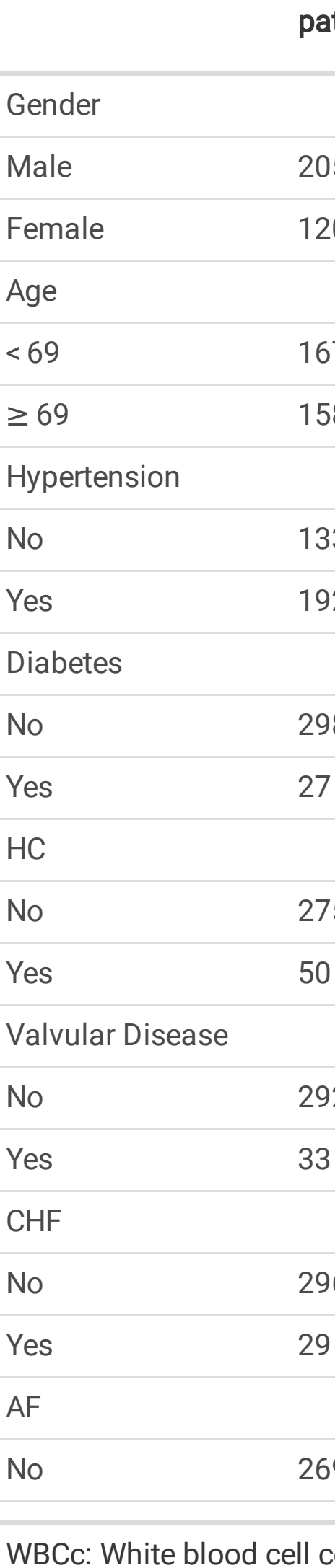

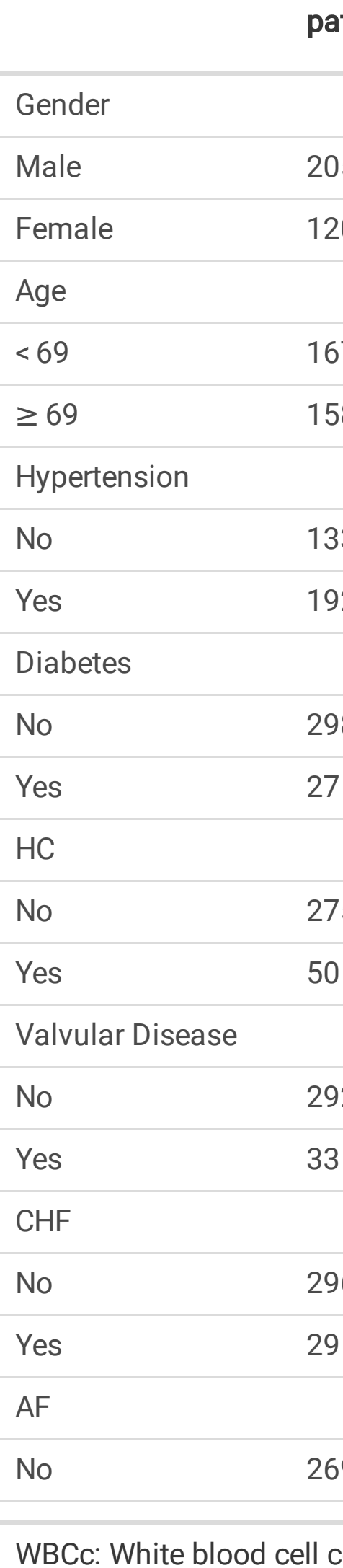

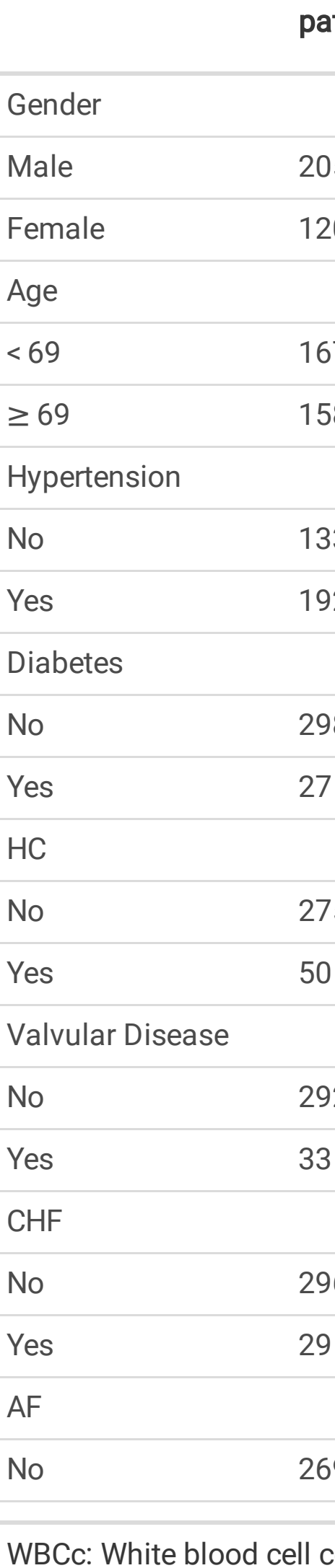

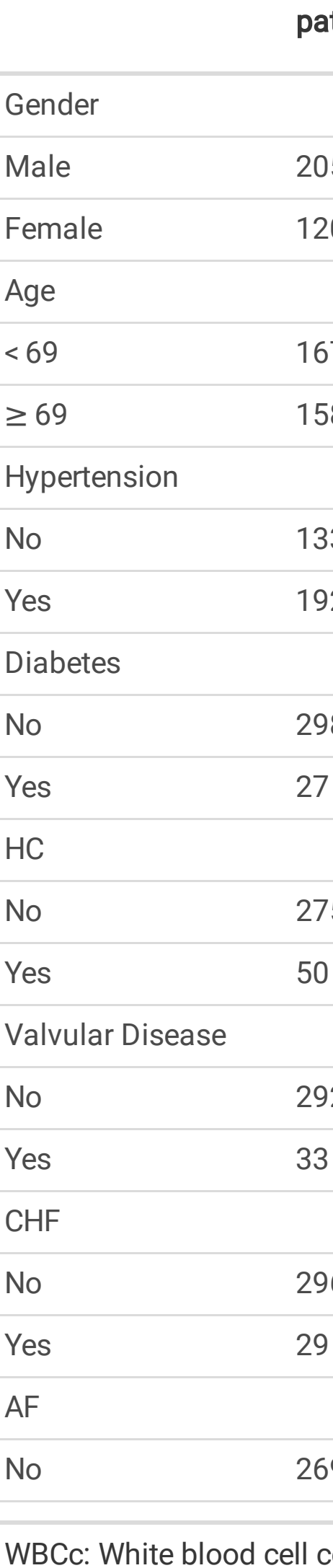

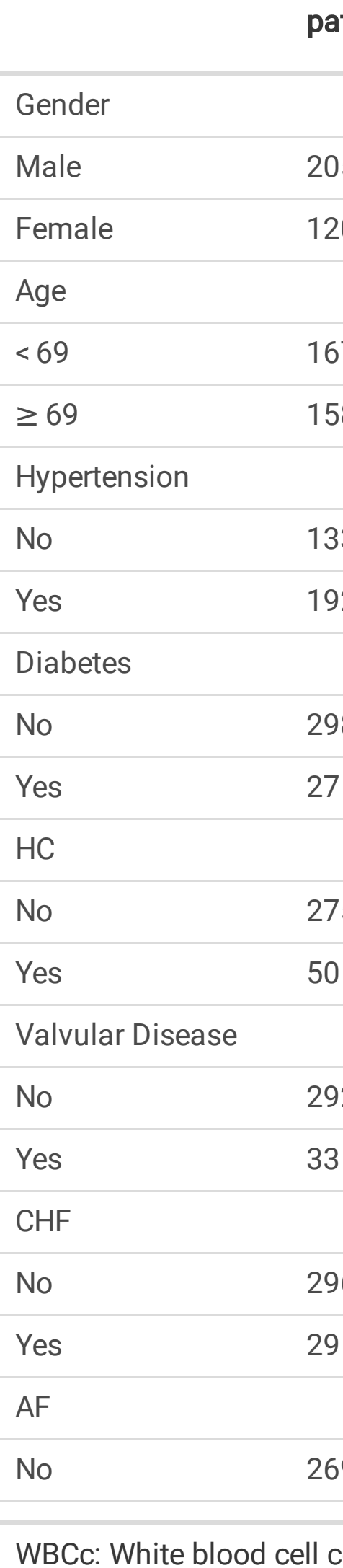

\begin{tabular}{lr} 
& pat \\
Gender & \\
Male & 205 \\
Female & 120 \\
Age & \\
$<69$ & 167 \\
$\geq 69$ & 158 \\
Hypertension & 133 \\
No & 192 \\
Yes & \\
Diabetes & 298 \\
No & 27 \\
Yes & 29 \\
HC & 29 \\
No & \\
Yes & 53 \\
Valvular Disease & \\
No & \\
Yes & 29 \\
CHF & \\
No & \\
Yes & \\
AF & \\
\hline No & \\
\hline
\end{tabular}

fibrillation; AKI: acute kidney injury; RRT: renal replacement therapy
0.676

$\begin{array}{lll}\text { ref } & 0.001 & 3.799(1.695-8.513) \\ \text { ref } & 0.550 & 1.392(0.471-4.113)\end{array}$

0.013

0.260

0.085

0.529

0.246

$\begin{array}{lll}\text { ref } & 0.003 & 2.843(1.416-5.709) \\ \text { ref } & 0.774 & 1.275(0.242-6.704)\end{array}$

0.119

$\begin{array}{lll}\text { ref } & 0.017 & 2.348(1.163-4.741) \\ \text { ref } & 0.999 & /\end{array}$

0.148

ref $\quad 0.011 \quad 2.504(1.230-5.098)$ 


\begin{tabular}{|c|c|c|c|c|c|}
\hline & \multirow{2}{*}{$\begin{array}{l}\text { Number } \\
\text { Of } \\
\text { patients }\end{array}$} & \multicolumn{3}{|l|}{ WBCc } & \multirow{2}{*}{$\begin{array}{l}p \text { for } \\
\text { interaction }\end{array}$} \\
\hline & & $\leq 11 \mathrm{~K} / \mathrm{uL}$ & p Value & $>11 \mathrm{~K} / \mathrm{uL}$ & \\
\hline Yes & 56 & ref & 0.153 & $2.960(0.668-13.118)$ & \\
\hline Liver disease & & & & & 1.000 \\
\hline No & 315 & ref & 0.002 & $2.738(1.429-5.248)$ & \\
\hline Yes & 10 & ref & 1.000 & 0.000 & \\
\hline $\begin{array}{l}\text { Respiratory } \\
\text { disease }\end{array}$ & & & & & 0.005 \\
\hline No & 262 & ref & 0.024 & $2.369(1.119-5.015)$ & \\
\hline Yes & 63 & ref & 0.043 & $3.844(1.046-14.127)$ & \\
\hline AKI & & & & & 0.216 \\
\hline No & 192 & ref & 0.004 & $3.458(1.473-8.121)$ & \\
\hline Yes & 133 & ref & 0.256 & $1.761(0.663-4.679)$ & \\
\hline RRT & & & & & 0.129 \\
\hline No & 296 & ref & 0.008 & $2.519(1.269-4.999)$ & \\
\hline Yes & 29 & ref & 0.270 & $2.833(0.445-18.042)$ & \\
\hline
\end{tabular}

\section{Figures}




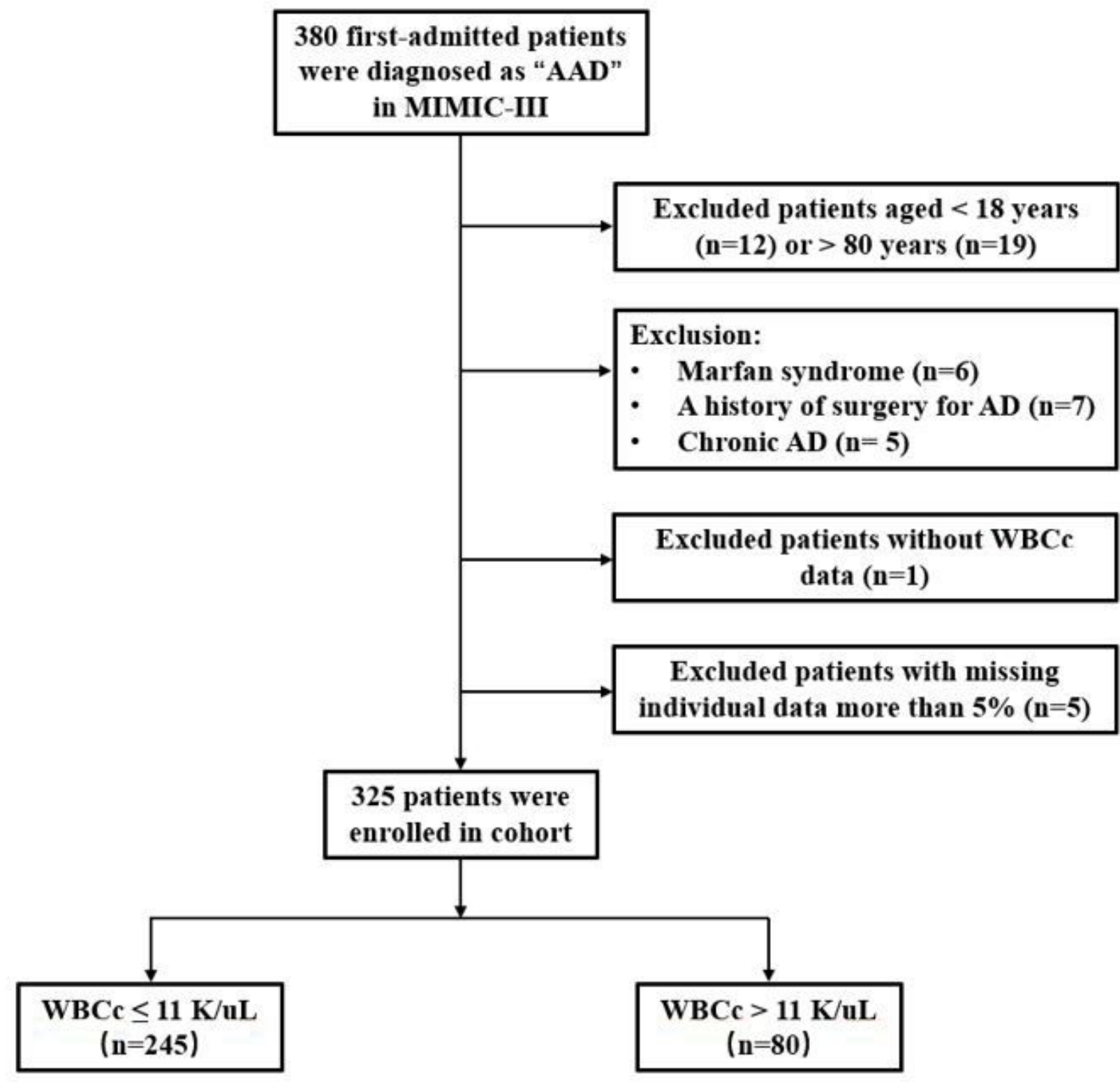

Figure 1

Study flow chart in the present study. AAD: acute aortic dissection; AD: aortic dissection; WBCc: white blood cell count. 
(a)

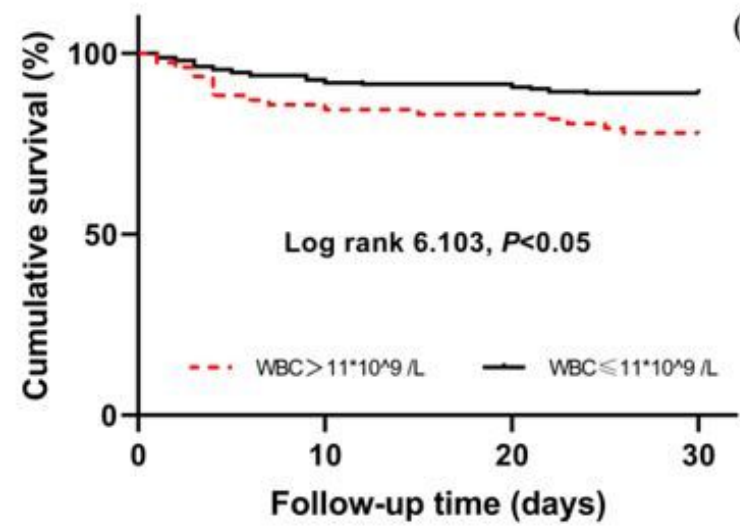

(c)

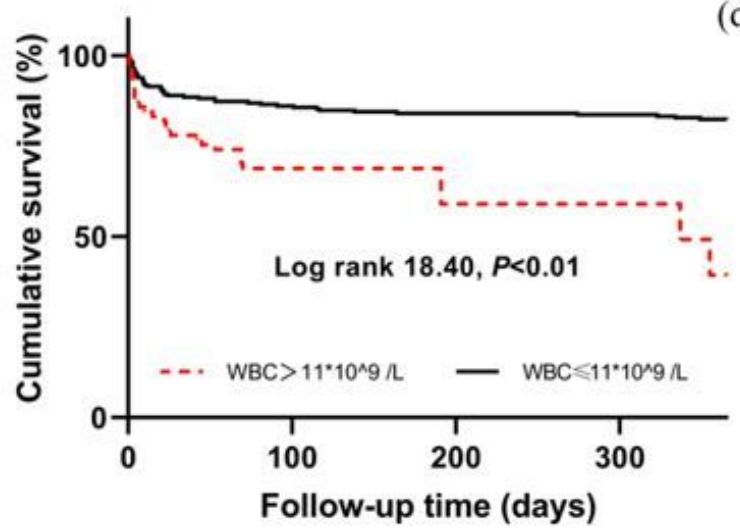

(b)

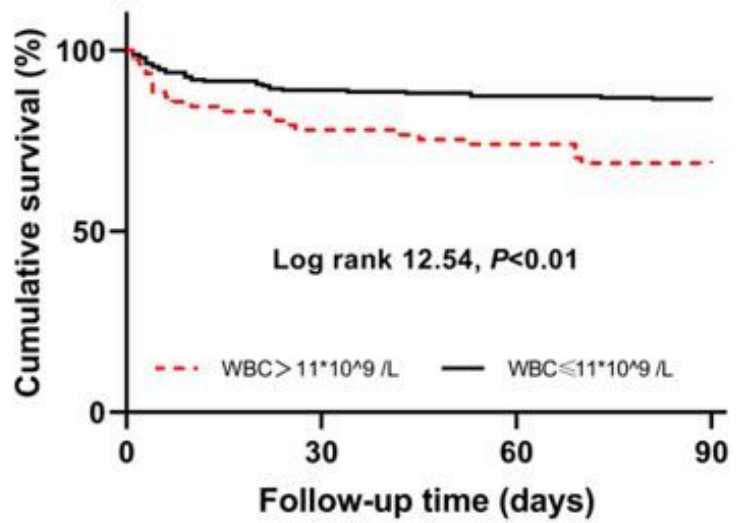

(d)

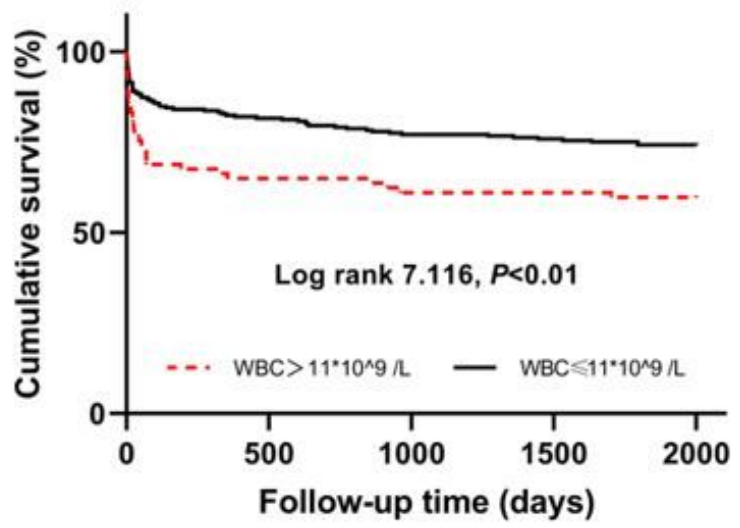

Figure 2

Kaplan-Meier curve for short- and long-term survival stratified by admission WBCc. 2a. 30-days survival rate was lower in high-WBCc group(log-rank $P<0.05)$; 2b. 90-days survival rate was lower in high-WBCc group(log-rank $P<0.01)$; 2c. 1-year survival rate was lower in high-WBCc group(log-rank $P<0.01)$; 2d. 5years survival rate was lower in high-WBCc group(log-rank $P<0.01)$; WBCc: white blood cell count.

\section{Supplementary Files}

This is a list of supplementary files associated with this preprint. Click to download.

- Table3.jpg 